\title{
Artefacts in ocean data hide rising temperatures
}

According to the myth - and a classic movie - Jason and his shipmates on the Argo suffered more than their fair share of reverses before bringing home the Golden Fleece. The international team of oceanographers working on the ambitious ARGO programme can surely sympathize. Instrumentation flaws have been discovered that undercut the programme's most striking finding to date. The problems have reinforced calls for caution when interpreting 'real-time' environmental data.

ARGO is an array of floats drifting freely around the oceans, 2,800-strong so far and still growing. Each float shuttles back and forth between the surface and the ocean depths measuring temperature and salinity, then sending data home via satellite when it is at the surface.

In 2006, data from the array led a team of scientists to the surprising conclusion that the world's oceans had cooled during 2003-05 - exceptionally warm years in terms of global surface temperature. The team published its findings in Geophysical Research Letters ${ }^{1}$. Such apparent cooling was seized on by people keen to highlight the uncertainties in forecasts of global warming ${ }^{2}$.

That cooling has now been shown to be an artefact. In some of the buoys - they are manufactured in separate batches - a software glitch caused the temperature and salinity data to be associated with the wrong depths. When the problem data are excluded from the analysis, the cooling trend drops below the level of statistical significance.
Novel observation technologies can often be error-prone. In 1997, for example, the discovery of a software problem involving NASA's TOPEX/ Poseidon satellite forced a number of groups to lower previously published estimates of global sea-level rise ${ }^{3}$. And until three years ago, calibration problems with data retrieved from different satellites led to an apparently striking discrepancy between temperature trends at Earth's surface and in the atmosphere ${ }^{4}$.

The ARGO problem is a reminder that rigid quality control is vital in such cases, says Keith Alverson, director of ARGO's parent agency, the Global Ocean Observing System at the United Nations Educational, Scientific and Cultural Organization in Paris. The ideal is to be able to compare a new analysis with an independent data stream, he adds.

The flaw occurred in a batch of floats fabricated at the Woods Hole Oceanographic Institution in Massachusetts. It was detected when the temperature profiles generated by ARGO were compared with historical data from the regions where the cooling seemed to be most pronounced.

The authors of the original report, led by John Lyman of the National Oceanic and Atmospheric Administration in Seattle, Washington, submitted a correction to Geophysical Research Letters on 9 April; this had not been published when Nature went to press. Apart from the spurious ARGO data, they report a newly discovered bias in temperature profiles from expandable bathythermographs (XBTs)

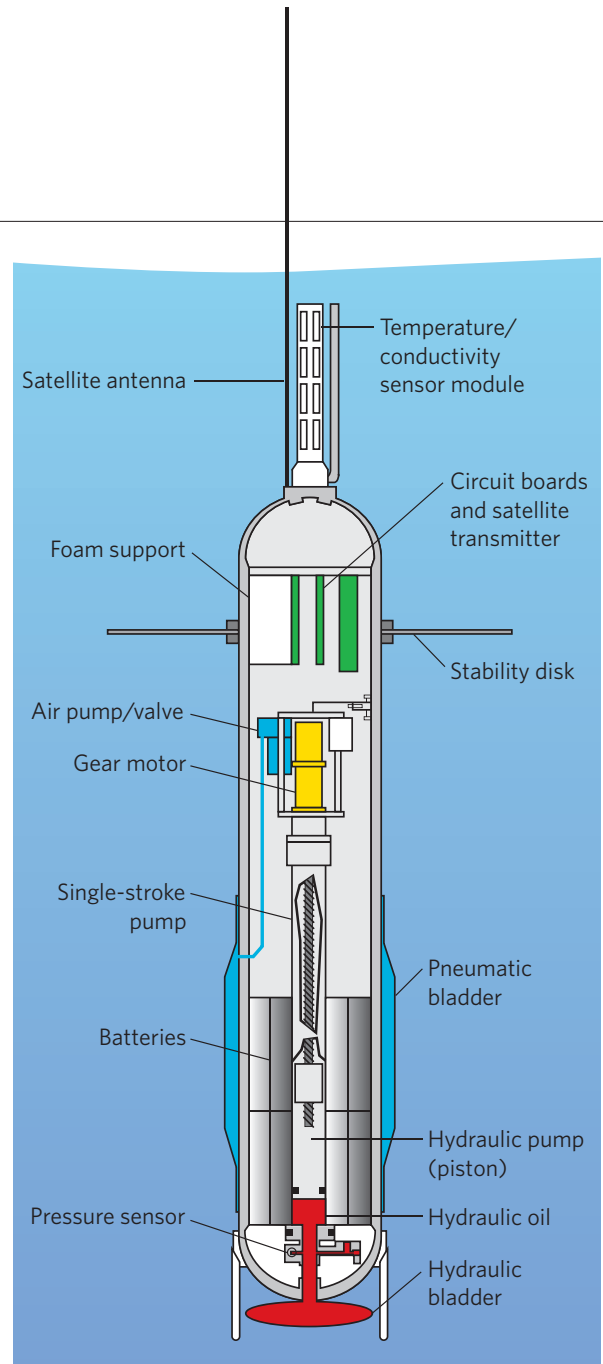

The ARGO array of almost 3,000 floats measures ocean temperature and salinity worldwide.

that were also used for the analysis. Inexpensive XBTs have been a major data source for many oceanographic studies. The two problems concealed each other, says Josh Willis, an oceanographer at the Jet Propulsion Laboratory in Pasadena, California, and a co-author of the report: "When I first became aware of the problem I was really horrified.”

\section{Reform makes Italian research accountable}

Italian research is headed for major reform - yet again. But this time it's for real, insists Luciano Modica, undersecretary of state for research, and the main architect of a reforming law that the Italian parliament is expected to pass by the end of May.

"The difference between this law and other attempts at reform is the element of autonomy," says Modica. For the first time, every research organization and institute will have full control over its budget, recruitment and how it runs its research. At the same time, the institutes will be accountable to the government for their decisions.

Universities were given autonomy in 1990, but without much accountability. Now there will be budgetary consequences for any university or research institute that makes bad decisions. The new law also creates an independent evaluation agency that will assess the quality of the research produced. And it gives the government power to withhold funds from institutes that do badly and to reward good performers with extra money.

"Not only money - also positions," says Modica, who this week created 1,600 positions for entrance-level professorships over the next three years.
These will be distributed to the universities ranked highest in Italy's first research assessment exercise, carried out in 2001-03. "The first ten universities in each field will get a certain number of these professorships, paid for by the government, and the others will get none," Modica says.

The decree also dictates that presidents of research agencies can no longer be simply named by the government, but will 
The ARGO Steering Team says that additional information sources should allow onethird of the biased profiles to be corrected exactly, and the remainder approximately. Until then, it is "not prudent" to use data from the ARGO array in combination with $\mathrm{XBTs}$, the authors recommend in their correction. Other studies done using the data will need to be re-examined in this light.

Yet oceanographers remain excited about ARGO's chances of delivering true gold, saying it is the best thing to happen to the field in decades. "Factor it in and move on," says Gavin Schmidt, a climate modeller at the NASA Goddard Institute for Space Studies in New York. But he adds that scientists do need to be more aware of things that can go wrong with new observation systems - particularly if anomalous results turn up.

So has the ocean warmed after all? Yes, but not by as much as had been thought before the flaw in the XBTs was found, says Viktor Gouretski, an oceanographer at the Alfred Wegener Institute of Polar and Marine Research in Bremerhaven, Germany. Gouretski has reanalysed historical data, correcting for the bias in the $\mathrm{XBTs}^{5}$. According to this work, the top 3,000 metres of the oceans warmed by some $0.03^{\circ} \mathrm{C}$ between 1957 and 1996 - around one-third less than when the bias was not taken into account.

The effect of the more recent bias in the ARGO data has yet to be worked out, however. "It's always a work in progress," says Schmidt.

Quirin Schiermeier

1. Lyman, J. M., Willis, J. K. \& Johnson, G. C. Geophys. Res Lett. 33, doi:10.1029/2006GL027033 (2006).

2. Nature $442,854-855$ (2006)

3. Nerem, R. S. Science 275, 1049-1053 (1997)

4. Fu, Q. et al. Nature 429,55-58 (2004).

5. Gouretski, V. \& Koltermann, K. P. Geophys. Res. Lett. 34 doi: 10.1029/2006GL027834 (2007).

be chosen from short lists drawn up by expert committees.

Among other things, this change is likely to lead to the ousting of Fabio Pistella, president of Italy's main research agency, the National Research Council. Constitutionally, such changes at the agency must be overseen by a temporary commissioner, not the incumbent president. A new president will then have to be appointed under the changed procedures once the commissioner's job is done. Pistella, who is not highly regarded, is unlikely to be on the post-reform short list.

Alison Abbott

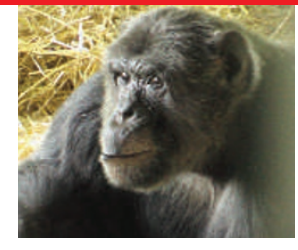

CHIMP DENIED A LEGAL GUARDIAN

Court turns down request in case aiming for 'ape rights'. www.nature.com/news

\section{India plans third Antarctic base}

GOA

Sometimes it's nice to catch up with your old neighbourhood, even if you have been gone for some time. Indian researchers are taking this desire to extremes with a campaign for a new Antarctic base in Princess Elizabeth Land - a part of the continent that, 120 million years ago, was contiguous with India's eastern coast. But the idea has been opposed by other countries and environmental groups.

Last year, India's proposal for such a base was turned down at an Antarctic Treaty Consultative Meeting (ATCM) in Edinburgh. Now the proposal has been resubmitted to this year's ATCM, which started in New Delhi on 30 April. "This time we have made a strong scientific case for locating the base in Larsemann Hills," says Rasik Ravindra, director of the National Centre for Antarctic and Ocean Research (NCAOR) in Goa, India.

But the Antarctic and Southern Ocean Coalition (ASOC), a pressure group based in Washington DC that opposes the Indian base, continues to voice doubts. "There have been concerns about the integration of India's plans with the plan for an ASMA (Antarctica Specially Managed Area) by Australia, China, Romania and Russia," says James Barnes, ASOC's Executive Director. Ravindra says that India favours the Larsemann Hills being designated as an ASMA, and would accept the special controls on environmental damage that such a classification would entail.

A 75-page environmental evaluation report prepared by NCAOR seeks to allay fears that the Indian station would harm the Antarctic environment. The effect, if any, would be only "minor or transitory", the report concludes. India would

be willing to quit the base in 25 years, removing all signs of its existence, says Ravindra.

Some Indian researchers think that other countries are trying to exclude them. "It is like entering an unreserved compartment in a train to find the seats are taken," says Ravindra. They think they were in first and so others must keep out." Prem Chand Pandey, former director of NCAOR, suspects that the powers in situ have an economic motive: "The area is very rich in hydrocarbons and those who

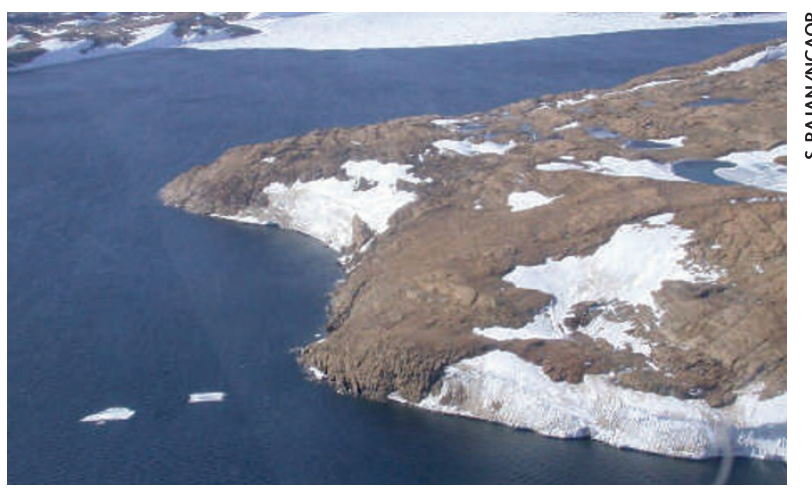

Home from home: India wants a research base in the Larsemann Hills.

are already in that area do not want others to come there." Although Antarctic resources cannot be exploited under the terms of the Antarctic treaty, that could change in the future.

One scientist notes that during Indian survey work in the area, helicopters from nearby Australian, Russian and Chinese bases were watching from above. These countries supported their opposition to the Indian base with the claim that the area had already suffered "human impacts." In a conciliatory move, Australia offered Indian researchers facilities at its station as an alternative to a new base But India declined the offer because it "would not have been practical" and because Indians preferred to have their own base, Rajan says. under investigation at magnetic observatories in Hungary and Denmark. The new base could also be a good ground station for the Indian ocean-observing satellite due to be launched in 2008.

But the main reason for selecting the site was to investigate how India broke away from Antarctica. Indian scientists hope that the Larsemann Hills will reveal vestiges of the Indian Mahanadi River, which flowed there about $\mathbf{1 3 0}$ million years ago when the continent was part of Gondwanaland. "The correlation between the two distant locations with respect to lithology, structure, tectonics and other geological constraints would help in fine-tuning the Gondwana fit," says Rajan. K. S. Jayaraman 